\title{
Deformation and fracture of a $\mathrm{Zr}-\mathrm{Al}-\mathrm{Cu}$ metallic glass ribbon under tension near glass transition temperature
}

\author{
Xue-feng Gao, Na Ge, Fu-yu Dong, Rui-chun Wang, and *Hong-wang Yang \\ School of Materials Science and Engineering, Shenyang University of Technology, Shenyang 110870, China
}

\begin{abstract}
The high temperature tensile and fracture behavior of $\mathrm{Zr}_{50} \mathrm{Al}_{40} \mathrm{Cu}_{10}$ metallic glass at the temperature range in the vicinity of glass transition were investigated. Tensile tests were carried out at room temperature, 350$420{ }^{\circ} \mathrm{C}$, and in the supercooled liquid region temperature range, respectively. Obvious plastic deformation was initiated at temperature about $80{ }^{\circ} \mathrm{C}$ lower than the glass transition temperature. The ultimate tensile strength decreases with the increase of testing temperature and the ductility increases with temperature. At temperature higher than $T_{g}$, viscous flow of Non-Newtonian fluid led to super plastic deformation behavior. The deformation process under tension was inhomogeneous, and remarkable serrations were observed on the stress-strain curve near glass transition temperature.
\end{abstract}

Key words: metallic glasses; high temperature mechanical properties; fracture behavior; plastic deformation CLC numbers: TG139 .8 Document code: $\mathrm{A}$

Article ID: 1672-6421(2018 03-216-06

\begin{abstract}
A morphous alloys have excellent mechanical properties compared with traditional crystalline alloys, such as high strength, superplasticity in the supercooled liquid region, good corrosion resistance and large elastic limit ${ }^{[1]}$. An amorphous alloy is a kind of metallic material with only a short-range order on the atomic scale. Because its microstructure is quite similar to that of glass and it forms from rapid cooling of metals, it is also called metallic glass ${ }^{[2-5]}$. Lack of typical defects for polycrystalline alloys, such as grain boundaries and dislocations, metallic glasses attract a lot of research interests on fabrication methods, properties and applications ${ }^{[6-8]}$. However, metallic glasses exhibit different deformation behavior under different loading conditions due to its metastable glassy nature. Its deformation behavior is especially sensitive to temperature and strain rate. Metallic glasses have no observable plastic deformation at room temperature and the ductility is almost zero especially under the condition
\end{abstract}

\footnotetext{
*Hong-wang Yang

Male, born in 1974, PhD, associate professor. His research interest mainly focuses on the development of metallic glasses with high glass forming ability, high temperature mechanical behavior and crystallization mechanisms of amorphous alloys.

E-mail: hwyang@sut.edu.cn.

Received: 2018-03-26; Accepted: 2018-05-10
}

of tension, even compression ${ }^{[9]}$. The limited plastic deformation under tension or compression is normally localized in a single primary shear band of about $10 \mathrm{~nm}$ thick, rendering no observable global plastic deformation. The localized shear banding introduces a brittle manner of rupture, causing catastrophic failure under loading higher than the strength as in ceramic materials. Thus, the practical application as structural materials is seriously restricted

The mechanical behavior and fracture of bulk metallic glasses at room temperature were widely investigated and in-depth fracture analysis was carried out. Zhang ${ }^{[10]}$ et al. found the existence of a large number of radial dimples in the tensile fracture surface in $\mathrm{Zr}$-based metallic glasses at room temperature. Wang ${ }^{[11]}$ et al. found that the tensile fracture morphology of Zr-based amorphous alloy presents a typical vein pattern.

A lot of efforts have also been made to enhance global plasticity or ductility of metallic glasses at room temperature. Zhang et al. ${ }^{[12]}$ introduced compression surface stresses to obstruct single primary shear band propagation and shear localization, the remarkable improvement of ductility was obtained in bulk metallic glasses. It is still difficult to achieve tensile ductility of monolithic metallic glasses. Guo et al. ${ }^{[13]}$ employed in situ transmission electron microscope to determine the deformation nature of the small-sized metallic glass under tension. For the $100 \mathrm{~nm}$ thick sample, great tensile 
ductility in the range of $23 \%-45 \%$ was observed, including significant uniform elongation and extensive necking or stable growth of the shear offset.

In the supercooled liquid region, which is defined as the temperature range between the glass transition $\left(T_{\mathrm{g}}\right)$ and onset of crystallization $\left(T_{\mathrm{x}}\right)$, an amorphous alloy exhibits excellent plastic deformability ${ }^{[14-18]}$. The deformation behavior in this temperature range was extensively studied due to the potential to forming Microelectromechanical systems (MEMS) parts by net shape processing. Inoue et $\mathrm{al}^{[19]}$ reported that $\mathrm{Zr}$-based amorphous alloys exhibited a wide supercooled liquid region and the superplastic behavior occurred in tensile loading.

The deformation and fracture behavior in the vicinity of glass transition temperature was seldom carried out. Investigating the transition of room temperature localized shear banding to high temperature homogenous flow will also contribute to understanding the challenging question of the nature of glass transition. However, the research of deformation behavior at this temperature range was mostly based on compression tests.

Therefore, it is necessary to study the deformation behavior near the glass transition temperature, in addition to studying the mechanical properties of the supercooled liquid region. In this paper, Zr-based metallic glassy ribbon was engaged to understand the deformation and fracture nature under tension near glass transition temperature. The deformation and fracture behavior of a $\mathrm{Zr}_{50} \mathrm{Cu}_{40} \mathrm{Al}_{10}$ metallic glass in the vicinity of glass transition temperature were studied.

\section{Experimental procedure}

$\mathrm{Zr}_{50} \mathrm{Al}_{40} \mathrm{Cu}_{10}$ (at.\%) ingots were prepared by arc melting pure $\mathrm{Zr}, \mathrm{Cu}$ and $\mathrm{Al}$ elements in an Ti-gettered $\mathrm{Ar}$ atmosphere and remelted 4-5 times to ensure the composition homogeneity. Melt spinning was performed using a laboratory-scale single roller melt-spinner operated in a purified Ar atmosphere. The samples with $\sim 4 \mathrm{~mm}$ in width and $40 \mu \mathrm{m}$ in thickness were used in the tensile tests. Glassy structure was identified by X-ray diffraction (XRD-7000 (S/L), Shimadzu). The initial thermal properties of the alloy were studied using a Differential Scanning Calorimetry (DSC-1, Mettler Toldeo) at a constant heating rate $\left(20^{\circ} \mathrm{C} \cdot \mathrm{min}^{-1}\right)$. Electronic universal testing machine (WDW$1 \mathrm{D}, \mathrm{SUNS}$ ) equipped with an electric furnace with temperature accuracy of $\pm 1{ }^{\circ} \mathrm{C}$ was used for tensile tests together with a pair of twin drum jigs, and the gauge length was set at $25 \mathrm{~mm}$. The initial strain rate was $3.33 \times 10^{-4} \mathrm{~s}^{-1}$. The ribbons used for the tensile test were kept in their original state, i.e. no grinding or polishing treatments were conducted on the surfaces or edges. High temperature tests were conducted after the samples were heated to the preset temperature, then hold for 10 minutes before loading. The fracture surfaces of the samples were observed with a high resolution field-emission scanning electron microscope (TM3030, Hitachi).

\section{Results}

\subsection{Characterization of as-spun samples}

The structure and thermal properties of the as-spun sample were characterized by XRD and DSC. As shown in Fig. 1(a), the XRD profile shows an obvious broad peak, which conforms to the amorphicity of the prepared alloy. The thermal property of the as-spun sample detected by DSC shows that the glass transition temperature $\left(T_{\mathrm{g}}\right)$ is $428{ }^{\circ} \mathrm{C}$ and the onset of crystallization temperature $\left(T_{\mathrm{x}}\right)$ is $505^{\circ} \mathrm{C}$. According to the DSC data, the tensile test experimental temperatures were set from $350{ }^{\circ} \mathrm{C}$ to $440{ }^{\circ} \mathrm{C}$, which are in the vicinity of the apparent glass transition temperature.
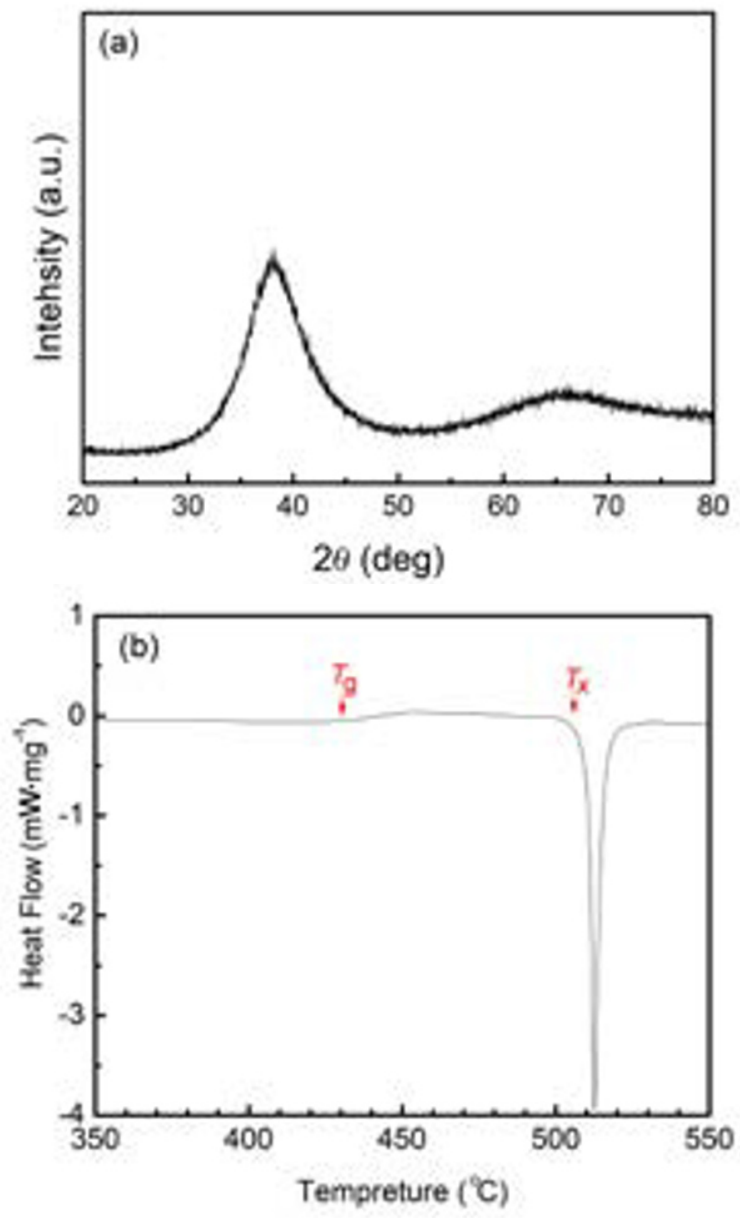

Fig. 1: XRD curve and DSC curve of $\mathrm{Zr}_{50} \mathrm{Cu}_{40} \mathrm{Al}_{10}$ metallic glass

\subsection{Tensile properties}

The stress-strain curves of $\mathrm{Zr}_{50} \mathrm{Cu}_{40} \mathrm{Al}_{10}$ metallic glass at initial strain rate of $3.33 \times 10^{-4} \mathrm{~s}^{-1}$ at different temperatures are shown in Fig. 2. The results indicate that the deformation behavior varies with testing temperatures. The sample exhibits a complete elastic deformation and an abrupt fracture with a tensile strength of about $745 \mathrm{MPa}$ at room temperature. At $350{ }^{\circ} \mathrm{C}$ and $370{ }^{\circ} \mathrm{C}$, the curves endure an elastic deformation and a small amount of plastic deformation with serrations and the tensile strength is $830 \mathrm{MPa}$ and $678 \mathrm{MPa}$, respectively. All the other curves 


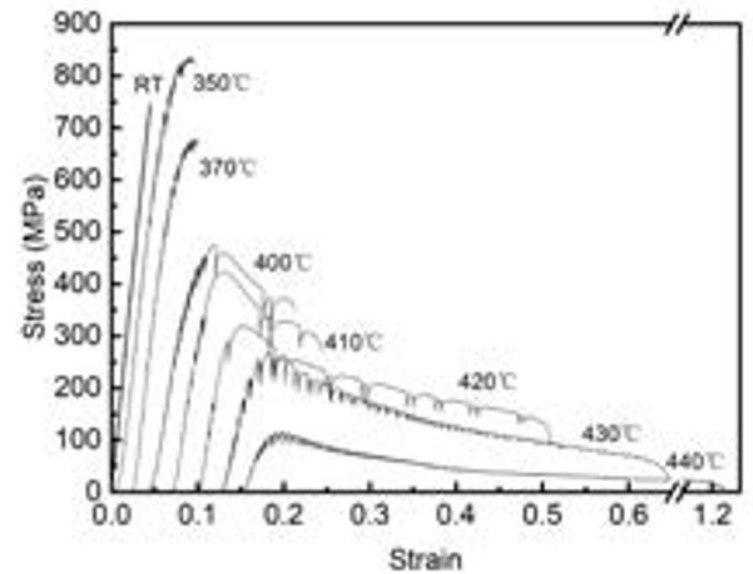

Fig. 2: Tensile stress-strain curves of $\mathrm{Zr}_{50} \mathrm{Cu}_{40} \mathrm{Al}_{10}$ at different temperatures

corresponding to tests from $400{ }^{\circ} \mathrm{C}$ to $440{ }^{\circ} \mathrm{C}$ show quite large plastic deformation following the elastic deformation and then strain induced softening can be observed.

At $430{ }^{\circ} \mathrm{C}$ and $440{ }^{\circ} \mathrm{C}$, which is within the supercooled liquid region, the plastic deformability of the sample is greatly improved and the necking is more obvious. The fracture regions of the samples tested at these temperature ranges deformed to sharp tips due to pure shear deformation behavior of excellent plasticity and low shear strength.

According to the above tensile stress-strain curve, the results of the tensile tests are summarized in Fig. 3. Figure 3(a) shows the variation of tensile strength with the testing temperature. The strength decreases with the increase of testing temperature. It is emphasized that strength reaches a maximum of $830 \mathrm{MPa}$ at $350{ }^{\circ} \mathrm{C}$ and drops sharply to $473 \mathrm{MPa}$ at $400{ }^{\circ} \mathrm{C}$. The trend of linear elastic strain and elongation with temperature are shown in the Fig. 3(b). The elastic strain decreases with the increase of temperature. The elastic strain decreased to $2.4 \%$ at 370 ${ }^{\circ} \mathrm{C}$. The elongation sharply increases with temperature within the supercooled liquid region. The ductility at $440{ }^{\circ} \mathrm{C}$ is about $107 \%$, which is about twice the amount of that of $430{ }^{\circ} \mathrm{C}$. With the increase of temperature, the strength of $\mathrm{Zr}_{50} \mathrm{Cu}_{40} \mathrm{Al}_{10}$ metallic glass gradually decreased, and the residue strain increased. The reason for the increase in strength at $350{ }^{\circ} \mathrm{C}$ compared with that at room temperature is detailed in the discussion section.

Tensile stress-strain curves (Fig. 2) show serrations at elevated temperatures. As the testing temperature increases, the serrated deformation became more uniform and denser. Figure 4 is a fragment of the tensile stress-strain curve of $\mathrm{Zr}_{50} \mathrm{Cu}_{40} \mathrm{Al}_{10}$ alloy at $420{ }^{\circ} \mathrm{C}$. The insert is a magnified view of its serrated deformation. The stress fluctuation $\Delta \sigma$ and the periodic strain spacing $\Delta \varepsilon$ between two adjacent serration are shown in the insert. Serrated deformation experiences a sudden drop in stress, and the magnified curve shows a vertical line in the graph. Then, the stress reverts to a little lower value with the un-dropped part. According to the dotted line (the slope of stress v.s. strain) in the figure, the initial slope during the stress recovery is almost the same as the initial elastic stage of the stress-strain curve. The
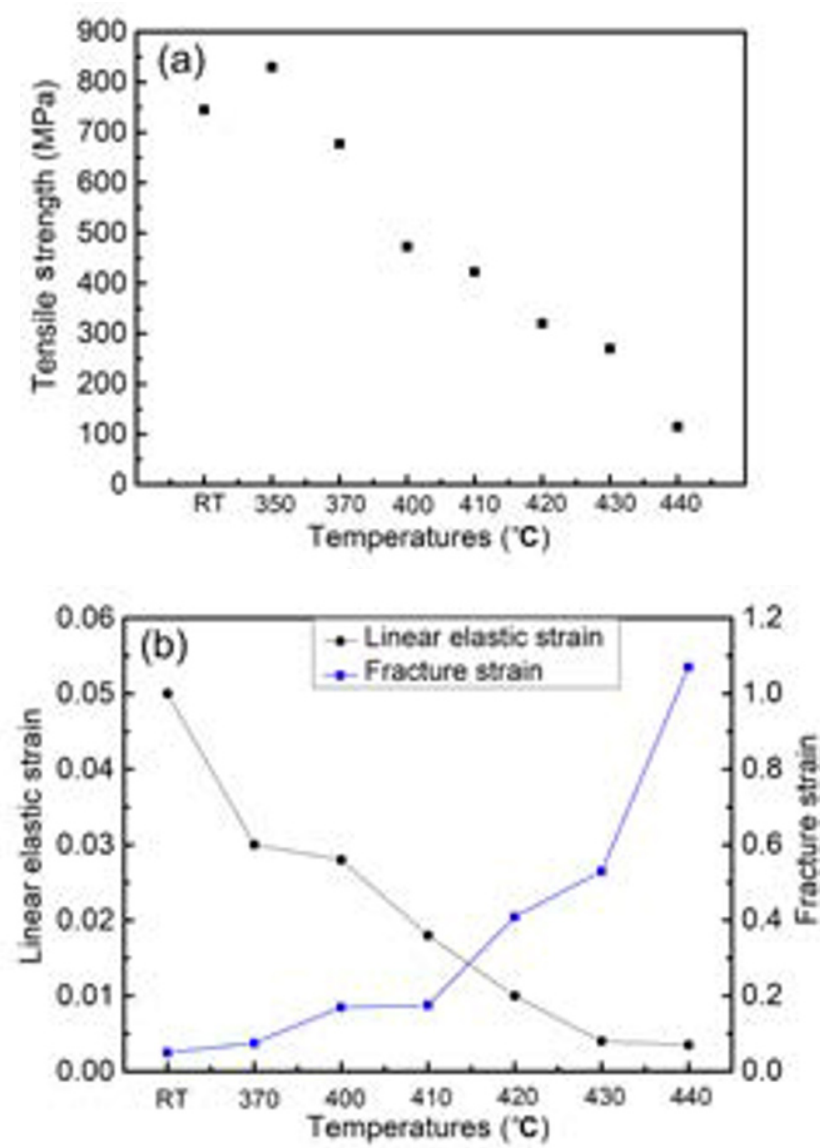

Fig. 3: Trend of tensile stress-strain data of $\mathrm{Zr}_{50} \mathrm{Cu}_{40} \mathrm{Al}_{10}$ amorphous alloy varies with temperature: (a) tensile strength, (b) linear elastic strain and fracture strain

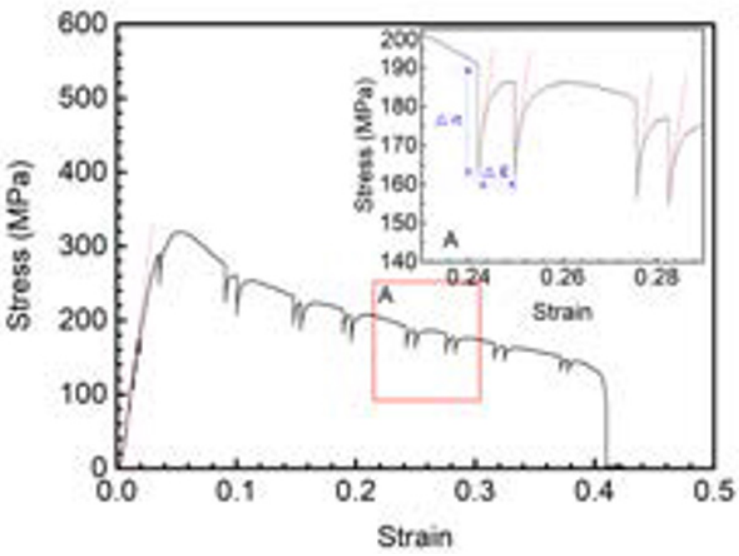

Fig. 4: Tensile stress-strain curve of $\mathrm{Zr}_{50} \mathrm{Cu}_{40} \mathrm{Al}_{10}$ at $420{ }^{\circ} \mathrm{C}$ (the insert is a partially magnified view of the serrations)

measurement of the inserted figure demonstrates that the $\Delta \sigma$ of the serrated curve is about $25.5 \mathrm{MPa}$, and the $\Delta \varepsilon$ is about 0.0077 . With the increase of strain, the vertical serration value become smaller, but the $\Delta \varepsilon$ remains almost unchanged.

\subsection{Fracture morphology}

Figure 5 shows the fracture morphologies of the $\mathrm{Zr}_{50} \mathrm{Cu}_{40} \mathrm{Al}_{10}$ metallic glass at different testing temperatures. As can be seen 
from Fig. 5(a), (b), and (c), the sample fracture morphologies show a typical vein pattern, which is similar to the fracture surface of most ductile amorphous alloy ribbons. Zhang ${ }^{[20]}$ et al. studied the fracture morphology of the Zr-based amorphous alloy at room temperature, which includes radial dimples. A pattern similar to that of a radial dimple can also be found from the Region A in Fig. 5(b) and (c). Moreover, it was found that the width of the veins significantly increased in the fracture morphology at $400{ }^{\circ} \mathrm{C}$ compared with that of $370{ }^{\circ} \mathrm{C}$.

In Fig. 5(d), some gray rough spots can be observed on both edges of the sample, which is caused by the oxidation of metallic elements due to the long period of exposure under high
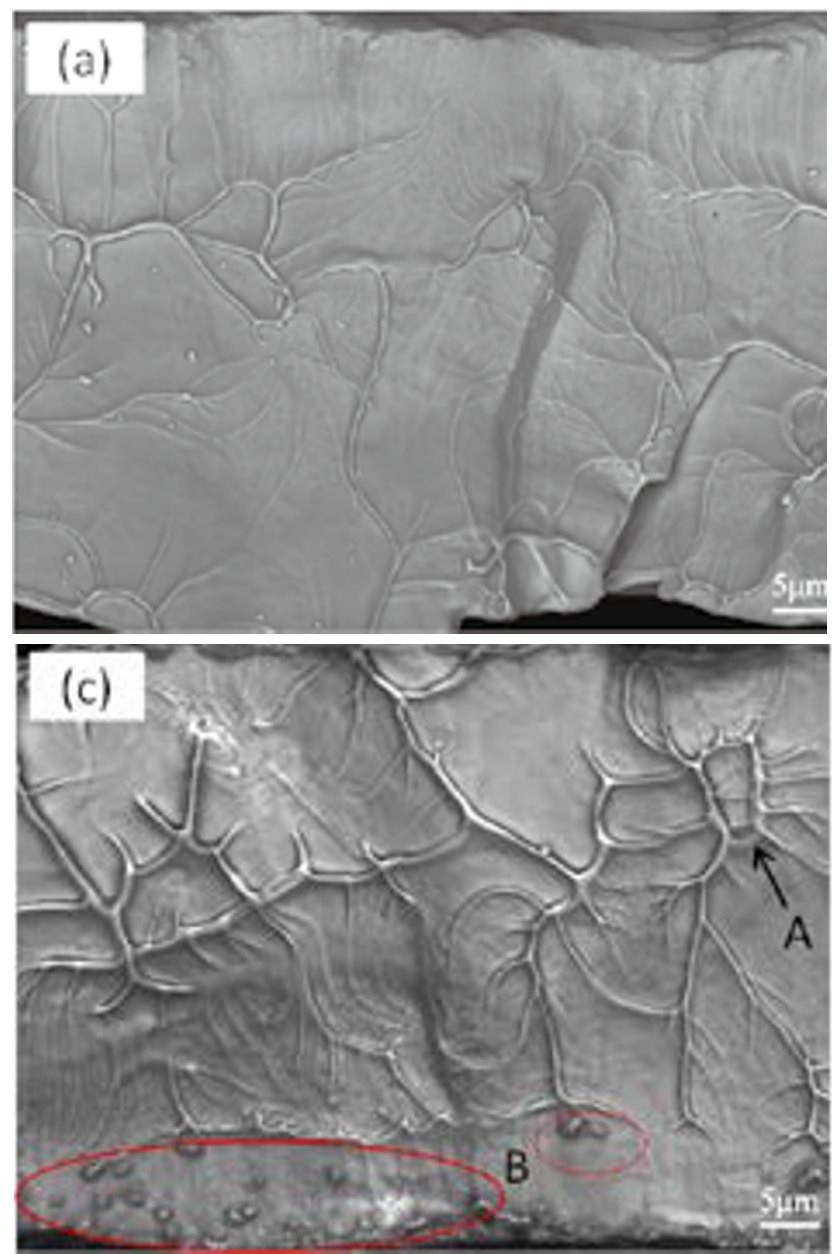

A

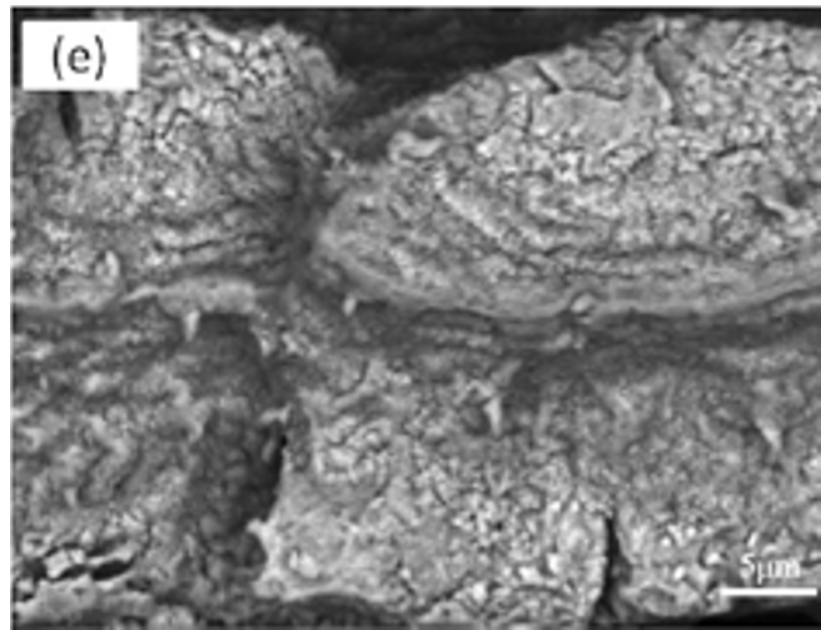

temperature and atmosphere. With careful observation, some likely gray spots was also observable on the Fig. 5(c) around the crack initiation area. With the increase of testing temperature to $430{ }^{\circ} \mathrm{C}$, the fracture surface obtained was fully covered by oxides due to higher temperature induced rapid oxidation kinetics. At this temperature or above, no vein patterns could be observed even in the latest fracture area of the center part, the fracture surface was fully covered by oxides.

\section{Discussion}

The deformation and fracture behaviors of metallic glasses

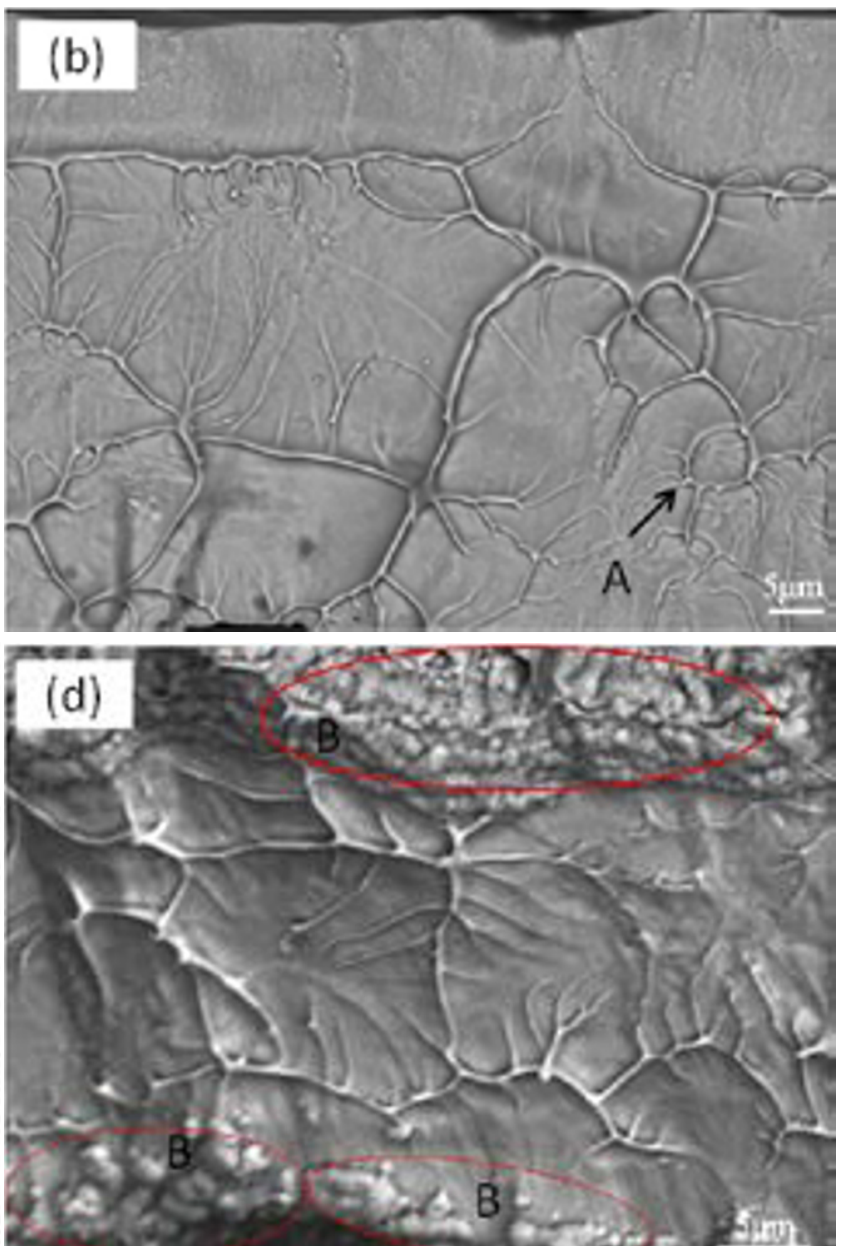

Fig. 5: SEM images of fracture surfaces of $\mathrm{Zr}_{50} \mathrm{Cu}_{40} \mathrm{Al}_{10}$ metallic glass: (a) at room temperature, (b) $370{ }^{\circ} \mathrm{C}$, (c) $400{ }^{\circ} \mathrm{C}$, (d) $420^{\circ} \mathrm{C}$, (e) $430^{\circ} \mathrm{C}$ 
are very sensitive to temperature and strain rate. At elevated temperature, the tensile curves undergo elastic and plastic deformations and final fracture. During the loading process, stress overshoot and serrated deformation appear with the change of temperature. Unlike Al-based metallic glassy ribbons, which show obvious strain hardening near the glass transition temperature at some certain strain rate range ${ }^{[21,22]}$, this alloy indicates obvious softening behavior with the increase of strain and much greater elongation in the supercooled liquid region.

According to the above experimental results, it was found that the deformation behavior of $\mathrm{Zr}_{50} \mathrm{Cu}_{40} \mathrm{Al}_{10}$ metal glass is quite different near the supercooled liquid region.

The tensile strength at room temperature for the present test is much lower than that reported by other researchers ${ }^{[23,24]}$ whose results of about 2,000 MPa were based on a compression test. This may be attributed to lower stress state softening parameter of tensile testing and high stress concentration caused by the raw rough state of test ribbons.

The shear resistance of the sample is reduced and the plastic deformation occurs during the loading process at elevated temperature. However, the strength tested at $350{ }^{\circ} \mathrm{C}$ is higher than that at room temperature. This abnormal phenomenon is ascribed to the less stress concentration introduced by the improvement of the material's plasticity at $350{ }^{\circ} \mathrm{C}$.

The plastic deformation and ductility of the sample increase at higher temperature, which reduces the shearing stress during the tensile test, resulting in the maximum strength $830 \mathrm{MPa}$ of the sample at $350{ }^{\circ} \mathrm{C}$. At $370{ }^{\circ} \mathrm{C}$, the tensile process of the sample is subjected to normal stress, the strength is up to 678 $\mathrm{MPa}$ and shows a small amount of plastic deformation. The atoms get higher thermal activation energy, the ability of atomic diffusion is enhanced and the stress softening occurs at 400 $-410{ }^{\circ} \mathrm{C}$. The fracture strength is obviously lower than the yield strength, and the plastic deformation ability increases.

The amount of atomic diffusion increased at $420-430{ }^{\circ} \mathrm{C}$ $\left(T_{\mathrm{g}}\right)$. In the loading, the deformation quickly transforms to the stable state and obtains great plastic deformation. At $440{ }^{\circ} \mathrm{C}$, the fracture strength of the sample is almost zero and the residual plastic strain is up to $107 \%$. The deformation behavior of the sample has been completely transformed into viscous flow. It also shows that the superplastic deformation of the sample is caused by viscous flow of supercooled liquid.

With thorough observation, we can find that after the elastic deformation, there are multiple periodic repeats of sudden drops in stress, that is, serrations on the stress-strain curve. Lewandowski summarized the deformation behavior of metallic glasses with shear strain rate and normalized testing temperature ${ }^{[25]}$. During the tensile test, the shear bands will be constantly activated, and the stress will suddenly drop down every time a shear band operates. However, the localized shear deformation zone does not expand quickly through the whole section; shear banding is obstructed at some points. Then new elastic and plastic deformation continues to occur. As shown in Fig. 4, the recovery of stress for every serrated deformation is consistent with the initial loading deformation behavior. This further indicates that the serrated flow is caused by a sharp shear band at each time, and then the sample follows the initial deformation behavior.

Actually, at a temperature near the glass transition temperature, two kinds of deformation, shear banding and viscous flow, coexist. With the increase of temperature, the deformation of the sample is transformed from shear deformation to viscous flow. Therefore both the serration height and the spacing decrease with the testing temperature.

\section{Conclusion}

The tensile test of the $\mathrm{Zr}_{50} \mathrm{Cu}_{40} \mathrm{Al}_{10}$ metallic glassy ribbon was carried out in the vicinity of the glass transition temperature. The deformation and fracture behavior of the sample varies with the testing temperature. At $350{ }^{\circ} \mathrm{C}$, which is about $80{ }^{\circ} \mathrm{C}$ lower than $T_{\mathrm{g}}$, obvious plastic deformation was also detected and therefore plastic deformation can be initiated at a temperature much lower than the glass transition temperature. The ultimate tensile strength decreases with the increase of testing temperature and the ductility increases with temperature; superplasticity was obtained above the glass transition temperature. At temperature higher than $T_{\mathrm{g}}$, homogeneous plastic deformation led to obvious necking. The fracture ends tapered to tips under shear stress attributed to low flow stress in the supercooled liquid region. The deformation process was inhomogeneous, remarkable serrations were observed on the stress-strain curve near glass transition temperature.

\section{References}

[1] Inoue A. Stabilization of metallic supercooled liquid and bulk amorphous alloys. Acta Materialia, 2000, 48(1): 279-306.

[2] Sun J, Zhang G, Liu G. Research progress in mechanical properties of bulk amorphous alloys. Journal of Xi'an Jiaotong University, 2001, 35(6): 640-645.

[3] Sun J F, Chen D M, Shen J, et al. Preparation and mechanical properties of $\mathrm{Zr}_{41.2} \mathrm{Ti}_{13.8} \mathrm{Cu}_{12.5} \mathrm{Ni}_{10} \mathrm{Be}_{22.5}$ bulk amorphous alloy. Journal of Solid Rocket Technology, 2002, 25(4): 56-55.

[4] Wang $X Y$, Sun L L, Li G, et al. Impurity diffusion of Mo in $\mathrm{Zr}_{57} \mathrm{Nb}_{5} \mathrm{Cu}_{15.4} \mathrm{Ni}_{12.6} \mathrm{Al}_{10}$ bulk metallic glass, Journal of Materials Science Letters 2003, 22(3): 171-173.

[5] Wang $X Y$, Sun L L, Liu R P, et al. Diffusion of Co in $\mathrm{Zr}_{46.75} \mathrm{Ti}_{8.25} \mathrm{Cu}_{7.5} \mathrm{Ni}_{10} \mathrm{Be}_{27.5}$ bulk metallic glass in supercooled liquid region under high pressure. Acta Physica Sinica, 2004, 53(11): 3845-3848

[6] Ashby M F, Greer A L. Metallic glasses as structural materials. Scripta Materialia, 2006, 54(3): 321-326.

[7] Inoue A, Takeuchi A. Recent development and application products of bulk glassy alloys. Acta Materialia, 2011, 59(6): 2243-2267.

[8] William J L. Bulk Glass-Forming Metallic Alloys: Science and Technology. Materials Research Society Bulletin, 1999, 24(10): 42-56.

[9] Xing L Q, Li Y, Ramesh K T, et al. Hufnagel, Enhanced plastic strain in Zr-based bulk amorphous alloys. Physical Review Letters, 2001, 64(18): 607-611.

[10] He G, Zhang Z F, Löser W, et al. Effect of Ta on glass 
formation, thermal stability and mechanical properties of a $\mathrm{Zr}_{52.25} \mathrm{Cu}_{28.5} \mathrm{Ni}_{4.75} \mathrm{Al}_{9.5} \mathrm{Ta}_{5}$ bulk metallic glass. Acta Materialia, 2003, 51(8): 2383-2395.

[11] Wang G, Shen J, Sun J F, et al. Tensile fracture characteristics and deformation behavior of a $\mathrm{Zr}$-based bulk metallic glass at high temperatures. Intermetallics, 2005, 13(6): 642-648.

[12] Zhang $Y$, Wang $W \mathrm{H}$, Greer A L. Making metallic glasses plastic by control of residual stress. Nature Materials, 2006, 5(11): 857-860.

[13] Guo H, Yan P F, Wang Y B, et al. Tensile ductility and necking of metallic glass. Nature Materials, 2007, 6(10): 735-739.

[14] Chu J P, Chiang C L, Mahalingam T, et al. Plastic flow and tensile ductility of a bulk amorphous $\mathrm{Zr}_{55} \mathrm{Al}_{10} \mathrm{Cu}_{30} \mathrm{Ni}_{5}$ alloy at 700 K. Scripta Materialia, 2003, 49(5): 435-440.

[15] Fu X L, Li Y, Schuh C A. Temperature, strain rate and reinforcement volume fraction dependence of plastic deformation in metallic glass matrix composites. Acta Materialia, 2007, 55(9): 3059-3071.

[16] Laws K J, Gun B, Ferry M. Mechanical stability of $\mathrm{Ca}_{65} \mathrm{Mg}_{15} \mathrm{Zn}_{20}$ bulk metallic glass during deformation in the supercooled liquid region. Materials Science \& Engineering A, 2008, 480(1): 198204.

[17] Lu J, Ravichandran G, Johnson W L.. Deformation behavior of the $\mathrm{Zr}_{41.2} \mathrm{Ti}_{3.8} \mathrm{Cu}_{2.5} \mathrm{Ni}_{10} \mathrm{Be}_{22.5}$ bulk metallic glass over a wide range of strain-rates and temperatures. Acta Materialia, 2003, 51(12): 3429-3443.
[18] Reger-Leonhard A, Heilmaier M, Eckert J. Newtonian flow of $\mathrm{Zr}_{55} \mathrm{Cu}_{30} \mathrm{Al}_{10} \mathrm{Ni}_{5}$ bulk metallic glassy alloys. Scripta Materialia. 2000, 43(5): 459-464.

[19] Schuh C A, Hufnagel T C, Ramamurty U. Mechanical behavior of amorphous alloys. Acta Materialia, 2007, 55(12): 4067-4109.

[20] Qu R T, Eckert J, Zhang Z F. Tensile fracture criterion of metallic glass. Journal of Applied Physics, 2011, 109(8): 869.

[21] Yang H W, Tan M J, Ramanujan R V. Strain hardening at elevated temperatures induced by dynamic crystallization of an $\mathrm{Al}_{88} \mathrm{Ni}_{4} \mathrm{Y}_{8}$ amorphous alloy. Scripta Materialia, 2012, 66(6): 382-385.

[22] Inoue A, Kim Y H, Masumoto T. A large tensile elongation induced by crystallization in an amorphous $\mathrm{Al}_{88} \mathrm{Ni}_{10} \mathrm{Ce}_{2}$ alloy. Materials Transactions, JIM 1992, 33(5): 487-490.

[23] Yokoyama Y, Inoue H, Fukaura K, et al. Relationship Between the Liquidus Surface and Structures of $\mathrm{Zr}-\mathrm{Cu}-\mathrm{Al}$ Bulk Amorphous Alloys. Materials Transactions JIM, 2002, 43(3): 575-579.

[24] Vormelker A H, Vatamanu O L, Kecskes L, et al. Effects of Test Temperature and Loading Conditions on the Tensile Properties of a Zr-Based Bulk Metallic Glass. Metallurgical \& Materials Transactions A, 2008, 39(8): 1922-1934.

[25] Huang C K, Lewandowski J J. Effects of Changes in Chemistry and Testing Temperature on Mechanical Behavior of AlBased Amorphous Alloy Ribbons. Metallurgical and Materials Transactions A: Physical Metallurgy and Materials Science, 2010, 41A(9): 2269-2275. 